\title{
OCCUPATIONAL HEALTH HAZARDS AMONG WORKERS OF GARMENT FACTORIES IN DHAKA CITY, BANGLADESH
}

\author{
KHAN NR ${ }^{1}$, DIPTI TR ${ }^{2}$, FERDOUSI SK ${ }^{3}$, HOSSAIN MZ ${ }^{4}$, FERDOUSI ${ }^{5}$, SONY SA ${ }^{6}$, AHMED S ${ }^{7}$, \\ PAUL $\mathrm{N}^{8}$, ISLAM MS ${ }^{9}$
}

\begin{abstract}
A cross-sectional study was conducted from January to June of 2013 to find out the occupational health hazards among the workers of different garment factories in Dhaka, Bangladesh. Total sample was 145 and purposive sampling technique was followed for data collection, which was done by face to face interview. The data was collected on a structured questionnaire. Data was analyzed by SPSS version 17.0. Majority (40\%) were found in the age group of 16-20 years where mean age was $23.30 \pm 6.92$ years. Among them female (89\%) outnumbered the male (11\%). Of them 96\% were Muslim. Majority (48.3\%) were educated up to primary school and most of them (55.9\%) were married. 91.7\% had monthly salary of 1001-5000 taka. 52.4\% respondents were machine operator, but maximum (75\%) were unskilled and $72 \%$ had length of job between 2-7 years. 91\% respondents normally worked for 8-9 hours. 85.5\% did 2-3 hours overtime. In the last one year $64.8 \%$ had no accident but minor cut, burn or injury was faced by 28.3\%. Most of the (44\%) respondents did not complain about physical environmental pollution but $33.8 \%$ complained of noise pollution. Majority (84.8\%) were satisfied with the constant presence of doctor or nurse in their factory. Maximum (51\%) respondents suffered from headache or shoulder pain. Insomnia was common in $20 \%$ respondents. Majority (56.6\%) did not mention any permanent illness. In this study the prevalence of occupational health hazards was $88.28 \%$. A significant relationship was found between noise pollution and headache $(P<0.014)$ and also between length of job (in years) \& backache $(P<0.091)$. More emphasis should be given to the workers to improve their health condition and working environment, so that they can increase their efficiency which can ultimately increase the production and add GDP to the country.
\end{abstract}

Key words: Occupational health, industrial health hazard, occupational health and safety, garment factory workers.

J Dhaka Med Coll. 2015; 24(1) : 36-43.

\section{Introduction}

Occupational health should aim at the promotion and maintenance of the highest degree of physical, mental and social well-being of workers in all occupations ${ }^{1}$. Modern concepts of occupational health embrace all types of employment including mercantile and commercial enterprises, service traders, forestry and agriculture and include the subjects of industrial hygiene, diseases and accidents, toxicology in relation to industrial hazards, industrial rehabilitation and

1. Dr. Nirmeen Rifat Khan, Associate Professor, Department of Community Medicine, Dhaka Medical College, Dhaka.

2. Dr. Tanjeem Rabika Dipti, MD-Resident student, Department of Pediatric Cardiology, Bangabandhu Sheikh Mujib Medical University (BSMMU), Dhaka.

3. Dr. Syeda Khaleda Ferdousi, Assistant Professor, Department of Community Medicine, Dhaka Medical College, Dhaka.

4. Dr. Mohammad Zaid Hossain, Associate Professor, Department of Medicine, Dhaka Medical College, Dhaka

5. Dr. Sultana Ferdousi, Associate Professor, Department Community Medicine, Nightingale Medical College, Dhaka

6. Dr. Sadia Akther Sony, MPH student, Department of Public Health and Informatics, Bangabandhu Sheikh Mujib Medical University (BSMMU), Dhaka.

7. Dr. Nahida Zafrin, Junior Consultant, Department of Medicine, Fenchugonj Upzala Health Complex, Sylhet.

8. Dr. Nandita Paul, Consultant, Sarkari Karmachari Hospital, Dhaka

9. Dr. Mohammad. Shohidul Islam, Lecturer, Community Medicine, Dhaka Medical College, Dhaka

Correspondence: Dr. Nirmeen Rifat Khan, Associate Professor, Department of Community Medicine, Dhaka Medical College, Dhaka. Cell Phone: +8801720044255. 
occupational psychology. One of the declared aims of occupational health is to provide a safe 'occupational environment' in order to safeguard the health of the workers and to step up industrial production ${ }^{1,2}$.

Basically, there are three types of interaction in a working environment: man and physical, chemical and biological agents; man and machine \&man and man $^{1}$. A hazard may be defined as anything with the potential to harm life, health or property ${ }^{2}$. Industrial health hazards are typically categorized into three classes: chemical hazards, in which the body absorbs toxin; ergonomic hazards such as those resulting from improper lifting or repetitive stress and physical hazards in which the worker is exposed to extreme temperature, atmospheric pressure, dangerous condition or excessive noise ${ }^{3}$.Work related injuries present a major public health problem resulting in serious socio-economic consequence that can be prevented if appropriate measures are taken. Annually throughout the world, an estimated number of 271 million people suffer from work related injuries and 2 million die as a consequence of these injuries ${ }^{1}$. The majority of the world's workforce does not have access to occupational health services. Only $5-10 \%$ of workplace in developing countries and $20-50 \%$ of workplace in developed countries have access to some kind of occupational health services.Small and medium scale industries employ about $80 \%$ of the workforce and contribute over $90 \%$ of all industries in developing countries ${ }^{2}$. Workers in these industries are at greater risk of work related injuries, chronic illness, stress and disability or death because of low educational and literacy rates, unfamiliarity with work process \& exposures and inadequate training ${ }^{4}$. Since 1919, the International Labor Organization (ILO) has maintained and developed a system of international labor standards aimed at promoting opportunities for women and men to obtain decent and productive work, in conditions of freedom, equity, security and dignity ${ }^{5}$.

Bangladesh has a thriving economy. These industries have huge men force working for them. More than $78 \%$ of Bangladesh's export earnings come from the garment industry ${ }^{6}$. According to 2010-11 survey of Bangladesh Garment Manufacturers and Exporters Association (BGMEA), Export Promotion Bureau, Bangladesh Bank, compiled by BGMEA, the number of garment factories are 5150, total number of workers is 3.6 million, products of about US $\$ 17914.46$ million is exported from ready-made garment factories and total US $\$ 22924.38$ million worth of products are exported, $79.15 \%$ of RMG's is utilized for national export. ${ }^{7}$ Generally in Bangladesh the garment workers suffer from vertigo, headache, low backache, joint pain, respiratory distress, anemia, female diseases, dysentery, needle prick injury, cut injury and burn injury. The occupational health problems affecting workers of our country, in fact workers of any developing country are liable to be much more complicated and dangerous as compared to that of developed countries ${ }^{2}$.

The government of Bangladesh is conscious about the need for a proper welfare program for the health, safety and welfare of the worker. These laws have been framed within the framework of the government policy and ILO conventions ratified by the government of Bangladesh.

The laws which regulate the health, safety and welfare provisions and working conditions of workers are: (1) The Factories Act, 1965; (2) Workmen's Compensation Act, 1923; (3) Tea Plantation Labour Ordinance, 1962; (4) Maternity Benefit Act, 1939; (5) The Dock Labourer's Act, 1934; (6) The Shops And Establishment's Act, 1965; (7) Minimum Wages Ordinance 1961; (8) Employment Of Children's Act, $1938^{8}$

The competitiveness of the garment industry in the world market is seriously affected by the ill health of the workers, since ill health decreases the labour productivity to a great extent.

Garment workers constitute a lion share of the total labour force in the country, which bring most of the country's foreign currency.

Occupational safety and health is important for moral, legal and financial reasons. Moral 
obligations would involve the protection of employee's lives and health. Legal reasons for occupational safety and health practices relate to the preventive, curative and compensatory effects of laws that protect worker's safety and health. Occupational Safety and Health can also reduce employee injury and illness related costs, including medical care, sick leave and disability benefit costs. ${ }^{11}$ If we can prevent the occupational health hazards we can ensure quality works done by the healthy workers with their efficiency and satisfaction. More workers will be encouraged to gain their skill in complex and challenging works when they will find assurance of healthy environment and health care facilities. In this way we can increase our productivity and finally our country will prosper in long run. We can achieve our economic development.

\section{Methods:}

A cross sectional study was done among the garment workers of Tejkunipara atTejgaonIndustrial Area and Dakshinkhan at Uttara in Dhaka, Bangladesh, from January to June of 2013. The sample size of the study was determined conveniently. The target population was the workers of both sexes in different garment factories. Among them final sample size was 145 from whom data were collected. Purposive sampling technique was followed for collecting data through face to face interview based on structured questionnaire, which includes all the relevant information. After collection of data, they were edited and processed manually. Then they were checked and verified for any omission, error or irrelevance. All data were entered and analyzed by computer with the help of SPSS version 17.0 and using relevant statistical tools and techniques.

\section{Results:}

Among 145 respondents, the highest 58 (40.0\%) respondents were found between the age group of 16-20 years and the least $2(1.4 \%)$ were found between the age group of 41-45 years. The mean age was $23.30 \pm 6.92$ years, ranging from 11-45 years. Among them $83 \%$ had permanent job and $17 \%$ had temporary job.6.9\% respondents had personal habit of smoking cigarette or biri. $13.8 \%$ respondents had habit of chewing betel leaf and jarda. Drinking excess tea or coffee was personal habit of another $8.3 \%$ respondents. $1.4 \%$ had habit of drinking alcohol or tari. Majority (57.2\%) had none of the above personal habits. Most ofthe respondents (44.1\%) had no problem with their physical environment. Other problems complained by the respondents have shown in table-I.

\section{Table-I}

Respondents' distribution regarding physical environment of the factory

\begin{tabular}{lcc}
\hline Physical environment & Frequency & Percentage \\
\hline Dirty & 13 & 9 \\
Inadequate light & 14 & 9.7 \\
Noise pollution & 49 & 33.8 \\
Inadequate ventilation & 6 & 4.1 \\
Overcrowding & 20 & 13.8 \\
Problem with safe & 23 & 15.9 \\
drinking water & & \\
Separate toilet not present & 8 & 5.5 \\
No problem & 64 & 44.1 \\
\hline
\end{tabular}

N.B. percentage exceeds due to multiple response

Majority(84.8\%) was satisfied with the constant presence of doctor or nurse in their factory. They also point out other facilities, such as, canteen facility $(80.7 \%)$, compulsory use of cap,mask and apron(80\%), primary treatment and free medication (78.6\%), maternity leave facility $(78.6 \%)$, day care centre facility $(64.1 \%)$ and so on. Only $1.4 \%$ complained of no facilities in their factory (table-II).

Among all respondents, $86.2 \%$ had training on how to exit during emergency. $75.2 \%$ respondents had training on extinguishing fire and $50.3 \%$ had training on first aid and health education. Only $2.8 \%$ respondents did not have any facilities to prevent accident in the factory they worked. $51 \%$ of respondents suffered from headache or shoulder pain in last one year (table-III).

Majority (64.1\%) did not mention any permanent illness, but few respondents $(20.7 \%)$ had been suffering from peptic ulcer disease, 
$11 \%$ had been suffering from depression, and $6.2 \%$ respondents from rheumatism, $4.8 \%$ had been suffering from hypertension and 0.7\% respondent had asthma.

Among 145 respondents, 51\% respondents implied that they suffered from headache in the last one year; a significant positive relationship was found between physical environment and headache(table-IV). Headache was found to be moderately associated with periodic health checkup. $44.3 \%$ of the respondents who received periodic health checkup complained of headache while $57.3 \%$ of the respondents who didn't received periodic health checkup complained of headache $(\mathrm{P}<0.116)$.

Among 145 respondents, 36 (24.8\%) respondents implied that they suffered from backache in the last 1 year, having a significant positive relationship between length of job (in year) and backache $(\mathrm{P}<0.09)$.

Table-II

Distribution of the respondents by the health care facilities available in the factory:

\begin{tabular}{lcc}
\hline Health care facilities & Frequency & Percentage \\
\hline Pre-placement examination & 64 & 44.1 \\
Periodic health checkup & 70 & 48.3 \\
Constant presence of doctor or nurse & 123 & 84.8 \\
Primary treatment and free medication & 114 & 78.6 \\
Health insurance & 19 & 13.1 \\
Maternity leave & 114 & 78.6 \\
Day care centre & 93 & 64.1 \\
Compulsory use of cap, mask and apron & 116 & 80 \\
Canteen facility & 117 & 80.7 \\
Others & 4 & 2.8 \\
No facilities & 2 & 1.4 \\
\hline
\end{tabular}

N.B. percentage exceeds due to multiple response

Table-III

Distribution of the respondents by the health problems (last one year)

\begin{tabular}{lcc}
\hline Health problems & Frequency & Percentage \\
\hline Headache or shoulder pain & 74 & 51 \\
Backache & 36 & 24.8 \\
Joint pain & 45 & 31 \\
Eye strain & 20 & 13.8 \\
Hearing problem & 12 & 8.3 \\
Gastroenteritis & 31 & 21.4 \\
Chest pain & 38 & 26.2 \\
Breathing difficulty & 5 & 3.4 \\
Skin disease & 8 & 5.5 \\
Tuberculosis & 4 & 2.8 \\
General weakness & 41 & 28.3 \\
Jaundice & 30 & 20.7 \\
Insomnia & 29 & 20 \\
Others(anorexia, lacrimation,typhoid etc.) & 3 & 2.1 \\
No problem & 20 & 13.8 \\
\hline
\end{tabular}

N.B. percentage exceeds due to multiple response 
Table-IV

Relationship between physical environment and headache

\begin{tabular}{|c|c|c|c|c|c|c|}
\hline & & \multicolumn{3}{|c|}{ Headache } & \multirow[t]{2}{*}{$\chi^{2}$} & \multirow[t]{2}{*}{$\mathrm{P}$ value } \\
\hline & & Yes & No & Total & & \\
\hline \multirow[t]{3}{*}{ Noise pollution } & Yes & $32(65.3 \%)$ & $17(34.7 \%)$ & $49(100 \%)$ & 6.032 & 0.014 \\
\hline & No & $42(43.8 \%)$ & $54(56.2 \%)$ & $96(100 \%)$ & & \\
\hline & Total & $74(51 \%)$ & $71(49 \%)$ & $145(100 \%)$ & & \\
\hline Inadequate & Yes & $5(83.3 \%)$ & $1(16.7 \%)$ & $6(100 \%)$ & 2.613 & 0.106 \\
\hline \multirow[t]{2}{*}{ ventilation } & No & $69(49.1 \%)$ & $70(50.9 \%)$ & $139(100 \%)$ & & \\
\hline & Total & $74(51 \%)$ & $71(49 \%)$ & $145(100 \%)$ & & \\
\hline Overall physical & At least one complain & $47(58 \%)$ & $34(42 \%)$ & $81(100 \%)$ & 3.588 & 0.058 \\
\hline \multirow[t]{2}{*}{ environment } & No complain & $27(42.2 \%)$ & $37(57.8 \%)$ & $64(100 \%)$ & & \\
\hline & Total & $74(51 \%)$ & $71(49 \%)$ & $145(100 \%)$ & & \\
\hline
\end{tabular}

N.B. percentage exceeds due to multiple response

\section{Discussion}

In this study,majority58 (40.0\%) were found in the age group of 16-20 years and the least 2 $(1.4 \%)$ were found in the age group of $41-45$ years. The mean age was $23.30 \pm 6.92$ years, ranging from 11-45 years. More or less similar picture was found in some other studies. Age profile by Jahan ${ }^{9}$ in her study showed that two thirds of the workers belong to the age group of 15-22 years. In another study done by Parimalam et al. ${ }^{10}$ found that relatively young age (28.2 \pm 6.8 years) were employed in cutting $\&$ stitching section of garment factories. In the present study $9(6.2 \%)$ respondents were found in the age group of 11-15 years. Under 16 years of age, these children should not be employed, according to "Employment of Children's Act 1938". Moreover they are inexperienced \& prone to injury. Joshi et al. ${ }^{11}$ also found $24.7 \%$ children less than 16 years of age in their study conducted in ten small scale industries of Kathmandu Valley. Some of the studies showed a higher age group of the worker. In Yashio city of Saitama, Japan, Nakata etal. ${ }^{12}$ found that a large number of worker $30.3 \%$ were in the age group 50-59 years. They showed that among 913 male respondents, younger age group (30-39 years) had increased risk (27\%) of occupational injury. The injury was enhanced by other factors also like current smoker $58.8 \%$, insomnia symptoms $23 \%$ and presence of physical and psychological diseases $28 \%$.

In this study about $89 \%$ were female workers, while only $11 \%$ were male. Most of the studies in garment factories revealed the dominance of female workers. We may predict that the female workers are satisfied with fewer wages and they are less demanding but they work sincerely. Parimalanet al. ${ }^{10}$ calculate the percentage of male and female workers in different sections of garment factories. In cutting section it was almost equal but in stitching and finishing section female were more, about $67 \%$ and $57 \%$ respectively. A reverse ratio of sex was observed in the study done by Tadesse\& Kumie ${ }^{4}$. They found 754 (78.4\%) males and 208 (22\%) females with a sex ratio $3.7: 1$ respectively.

Present study showed 81 (55.9\%) were married and 62 (42.8\%) were unmarried. While, Jahan $\mathrm{M}^{9}$ in her study found that out of 30 women, 19 $(63.3 \%)$ were unmarried, $9(30 \%)$ were married. In general, married persons are preoccupied with different marital, psychosocial and economic problems. They are more prone to occupational injury. However, Nakata et al. ${ }^{12}$ surprisingly found that, out of 385 females being unmarried $(26.7 \%)$, higher educational status $(53.7 \%)$ and insomnia symptoms (24\%) were strong factors associated with injury. 
The study showed maximum number of respondents $70(43.3 \%)$ was educated up to primary school. A few number, 22 (15.2\%) respondents were illiterate. $120(83 \%)$ respondents had permanent job, only $25(17 \%)$ had temporary job. Highest 76 (52.4\%) respondents worked as machine operator, and $41(28.3 \%)$ worked as helper. Yet, $109(75 \%)$ of the respondents were unskilled and $36(25 \%)$ were skilled. It seems that without or with some training the factory owners give permanent appointment to the worker as a machine operator. A little bit different picture was found in the study done by Jahan ${ }^{9}$. A higher percentage was found in the study done by Tadesse\& Kumie ${ }^{4}$. About 161 (50.2\%) and 295 $(46 \%)$ respondents of two different industries had attended secondary school respectively. Joshi et al. ${ }^{11}$ found that majority of the workers were illiterate and earned less than NRs. 5000 a month.

Similarly, in this present study the salary structure was highest among the lower middle class group whose monthly salary was 1001$5000 /$ - and the percentage was $91.7 \%$. Most of the workers had length of job for 2-7 years and their percentage was $49.7 \%$. Only $2(1.4 \%)$ had length of job more than 20 years. Maximum number of workers 132 (91\%) performed their duties for 8-9 hours. But sometimes 124 $(85.5 \%)$ workers had to do overwork for 2-3 hours more. For this they get extra monitory benefit and tiffin. With a fewer wage and extended working hour the workers do not want to continue their job for a longer period. Akhter et al. ${ }^{13}$ found significant relation for wage category and health problem, where $\mathrm{P}$ value was 0.35 . Thomas ${ }^{14}$ pointed that, women contribute a substantial amount towards family income. In his study $63 \%$ women were earning less than Rs. 3500/- per month and only 36.6\% women had more than Rs. 5000/- per month. This picture was very close to our study.

On reviewing accidents faced by the respondents, we found that 94 (64.8\%) did not face any accidents in the last one year. $41(28.3 \%)$ had minor injury/cut/burn. Chandra $\&$ Parvez ${ }^{15}$ did a comparative study on male and female workers between $30-35$ years. They observed some environmental factors which cause occupational injury or, accident to the workers. Injury with machine needles was found to be more among the workers -male $54.5 \%$ and female $45.4 \%$. They observed other accidents such as, injury by scissors, electric shock more among female (12.7\%), by electric wires, superficial burn more among male (10.9\%), too much noise, dust problem due to improper ventilation and problem due to vibration. Parimalamet al. ${ }^{10}$ also reported some accidents along with other health problems. Of them a high percentage, $78 \%$ had needle piercing injury. It seems that they are not using protective measures and also the workers were not skilled enough to that particular work or may be mentally disturbed otherwise. Tadesseet al. ${ }^{4}$ revealed that out of 322 injured respondents within one year, 55 (17.1\%) were hospitalized and $40 \%$ remained in hospital for more than 24 hours. Major injury was 3 (2.1\%) in our study.

To prevent accidents, $125(86.2 \%)$ got training how to exit during emergency, $109(75.2 \%)$ had training on extinguishing fire, 73 (50.3\%) had training on first aid and health education. A few number $4(2.8 \%)$ complained that facilities were totally absent. Akteret al. ${ }^{13}$ mentioned fire accidents were more frequent in garment factories. Jahan ${ }^{9}$ also observed that firefighting equipment were minimal in all the garments.

Different health problems in last one year were detected among the workers, maximum 74 $(51 \%)$ respondents suffered from headache or shoulder pain, 45 (31\%) suffered from joint pain, $41(28.3 \%)$ complained of general weakness, $38(26.2 \%)$ chest pain, $36(24.8 \%)$ backache, $31(21.4 \%)$ gastroenteritis, 30 (20.7\%) jaundice, $29(20 \%)$ insomnia, 20 (13.8\%) eye strain, 12 $(8.3 \%)$ hearing problem, $8(5.5 \%)$ skin disease, breathing difficulty $5(3.4 \%)$ and tuberculosis 4 $(2.8 \%), 20(13.8 \%)$ respondents had no problem in last one year.Similar findings were found in the studies conducted by Akteret al. ${ }^{13}$, Parimalam et al. ${ }^{10}$, Jahan ${ }^{9}$, Thomas ${ }^{14}$, Joshi et al. ${ }^{11}$ and Chand ${ }^{16}$.

This study revealed that most of the respondents received proper health care facilities. This will certainly minimize health 
problems among the workers. Maximum workers $(84.8 \%)$ got medical services by constant presence of doctor or, nurses. $78.6 \%$ workers received primary treatment and free medication. $48.3 \%$ had periodic health checkup, $44.1 \%$ had pre-placement examination. About $78.6 \%$ female workers had maternity leave and $64.1 \%$ female worker availed day care facilities. $80.7 \%$ workers were satisfied with canteen facilities which are essential to maintain sound health. $80 \%$ found to use cap, mask and apron to prevent dust borne diseases. Health insurance was provided to $13.1 \%$ respondents.A dissimilar picture was found in two studies. About health care facilities Akhter et al. ${ }^{13}$ found that $43 \%$ did not know about the medical facilities, $13 \%$ workers were not getting proper medical care, only $44 \%$ were getting first aid treatment. Female availed only 30 days maternity leave.Jahan ${ }^{9}$ found that the workers of 5 garment factories were deprived of treatment facilities. All the factories had first aid box to take care of minor accidents but regular doctor was absent. Child care facilities were also absent. Only one garment strictly enforced in wearing of masks and gloves but others did not provide masks to the workers. All the factories were devoid of canteen facilities.

In this study $44.1 \%$ respondents had no problem with their physical environment. $33.8 \%$ complained of noise pollution. Overcrowding in workplace $(13.8 \%)$, problem with safe drinking water $(15.9 \%)$, inadequate light $(9.7 \%)$ and inadequate ventilation (4.1\%), dirty workplace (9\%), no separate toilet facilities $(5.5 \%)$ all these were environmental problems which may lead to different health problems of the workers.

More or less similar environmental problems were found by Jahan ${ }^{9}$. Only one factory was overcrowded, congested, poorly ventilated and workers also complained noise pollution. All the factories were devoid of adequate toilets and safe drinking water.

Joshi et al. ${ }^{11}$ in their study found that major causes of occupational hazards were due to long working hour, unsafe working conditions, lack of supervision and training, use of old machinery and equipment, overcrowded production unit with very congested space, working with machines and equipment, use of electricity, use of chemicals in industries and dusty work sites.

We also searched for permanent illness among the respondents such as peptic ulcer 30 $(20.7 \%)$, depressive illness 16 (11\%) hypertension $7(4.8 \%)$, rheumatism $9(6.2 \%)$, asthma $1(0.7 \%)$, heart disease $2(1.4 \%)$. Maximum 93 (64.1\%) respondents had none of the above mentioned permanent illness or, any other illness. Thomas ${ }^{14}$ also found similar type of findings, where $12.66 \%$ had knee pain, $5.096 \%$ had stomach pain and $1.9 \%$ suffered from blood pressure, 30\% affected by asthma, $35 \%$ had stretch of job, $0.82 \%$ experienced mental tension. Chand ${ }^{16}$ also found some other illness, like obesity, bladder and kidney problem and psychological stress.

Our study showed the prevalence of occupational health hazards both occupational accidents and health problems about 128 $(88.28 \%)$ in the previous 1 year period. Nakata et al. ${ }^{12}$ found only the prevalence of occupational injury among the workers was $35.6 \%$. They statistically found that males $(43 \%)$ had a higher injury rate than female (17\%). All these permanent illness and health problems may develop due to chronic exposure of physical environmental factors. These illnesses can be screened by pre-placement health examination and minimized by periodic health checkup. Other health facilities must reduce the health problems and these illnesses. Health and safety training and regular supervision of workplace also improve the present condition of the workers and the workplace.

\section{Conclusion}

Our study reveals the occupational health hazards among workers of garment factories in Dhaka city. The study has conducted under such a circumstance when a great havoc took place in "Rana Plaza" at Savar near Dhaka city, where more than thousands of garment workers died and many of them were physically and mentally injured. As these garments are highest export earner of our country, this 
incidence must alert the garment owners, as well as, the government of Bangladesh about occupational safety-security, health and welfare of the workers. In our study majority are found in the age group of 16-20 years and most of them are female. These young female workers have access to employment but their poor working environments, low wages and occupational hazards exposure make them vulnerable to certain risks. Majority was satisfied with their health care facilities, which is really encouraging. Occupational health hazards may be due to chronic exposure of physical environmental factors. Preplacement health examination, periodic health checkup, health education and safety training and regular supervision of workplace can improve the efficiency of the workers. Prosperity and productivity of the industry solely depend on the health condition of the workers. Hence, improvement in health status of garment workers is necessary for our national economic development.

\section{References}

1. Park K. Park's Textbook of Preventive and Social Medicine. $21^{\text {st }}$ ed. New Delhi: 2011: p.744.

2. Center for Occupational and Environmental Health.Manchester, UK: University of Manchester;2007.

3. Nahar N, Ali RN, Begum F. Occupational health hazards in garment sector. Int J Bio Res2010; $1(2): 2$.

4. Tadesse T, Kumie A. Prevalence and factors affecting work-related injury among workers engaged in Small and Medium-Scale Industries in Gondar Wereda, North Gondar zone, Amhara Regional State, Ethiopia. Ethiop J Health Dev 2007; 21(1): 25.

5. ILO. Introduction to International Labour Standards. [Online]. 2011 Available from: www.ilo.org global/standards/introduction-to international-labour-standards / lang-en / index.htm (Accessed on 20 March, 2011).

6. Ahmed F. Improving social compliance in Bangladesh's ready-made garment Industry. J BGMEA; 2012; 1(1): 1-2.

7. Bangladesh Statistical Pocket Book 2011. Ministry of Planning, Government of People's Republic of Bangladesh. Dhaka, Bangladesh: 2011: p.176.

8. Rashid, Khabir, Hyder. Textbook of community medicine and public health. $4^{\text {th }}$ ed. 2004: p.19.

9. Jahan M. Women Workers in Bangladesh Garments Industry; a study of the work environment.Int J SocSci Tomorrow (3): 1-5.

10. Parimalam P, Kamalamma N, Ganguli AK. Knowledge, Attitude and Practices related to occupational health problems among garment workers in Tamil Nadu, India. J Occup Health 2007; 528-34.

11. Joshi SK, Shrestha S, Vaidya S. Occupational Safety and health studies in Nepal. Int J Occup Study Health 2011; 1: 19-26.

12. Nakata A, Ikeda T, Takahashi M, Haratani T, Hojou $M$, Swanson NG, et al. The prevalence and correlates of occupational injuries in small scale manufacturing enterprises. J Occup Health 2006; 48: 366-76.

13. Akhter S, Salahuddin AFM, Iqbal M, Malek ABMA, Jahan N. Health and occupational safety for female work force of garment industries in Bangladesh. $\mathrm{J}$ MechEngin 2010; 41(1): 65-70.

14. Thomas S. A study of health problems of women working in a textile unit in Coimbatore. Int $\mathrm{J}$ Sci Tech 2011; 1(5): 200-3.

15. Chandra N, Parvez R. Occupational health hazards among male and female sewing machine operators in a garment manufacturing units. IntJ MultiRes 2011; 1(3): 96-100.

16. Chand A. Physical and psychological health problems of garment workers in the Fiji. Pacific Public Health 2006; 13(2): 65-70. 